\title{
Synergy Between Vitamin D and Sex Hormones in Respiratory Functionality of Patients Affected by COVID-19
}

\begin{abstract}
Daniela Peruzzu ${ }^{1+}$, Maria Teresa Pagano ${ }^{1 \dagger}$, Marina Pierdominici ${ }^{1}$, Anna Ruggieri ${ }^{1}$, Andrea Antinori ${ }^{2}$, Gianpiero D'Offizi ${ }^{2}$, Nicola Petrosillo ${ }^{2}$, Fabrizio Palmieri ${ }^{2}$, Pierluca Piselli ${ }^{2}$, Evangelo Boumis ${ }^{2}$, Stefania Notari ${ }^{2}$, Emanuele Nicastri ${ }^{2}$, Chiara Agrati ${ }^{2}$, Giuseppe Ippolito ${ }^{2}$, Maria Cristina Gagliardi ${ }^{1 *}$, Maria Rosaria Capobianchi ${ }^{2}$ and Elena Ortona ${ }^{1}$ INMI-ISS COVID-19 Team

${ }^{1}$ Center for Gender Specific Medicine, Istituto Superiore di Sanità, Rome, Italy, ${ }^{2}$ National Institute for Infectious Diseases, Lazzaro Spallanzani, IRCCS, Rome, Italy
\end{abstract}

OPEN ACCESS

Edited by: Geoffrey Brown University of Birmingham, United Kingdom

Reviewed by: Maurizio Simmaco,

Sapienza University of Rome, Italy Sandro La Vignera, University of Catania, Italy

*Correspondence:

Maria Cristina Gagliardi mariacristina.gagliardi@iss.it

${ }^{+}$These authors have contributed equally to this work

Specialty section: This article was submitted to Experimental Pharmacology and Drug Discovery,

a section of the journal Frontiers in Pharmacology

Received: 21 March 2021 Accepted: 28 April 2021 Published: 13 May 2021

Citation:

Peruzzu D, Pagano MT,

Pierdominici $M$, Ruggieri A, Antinori A, D'Offizi G, Petrosillo N, Palmieri F,

Piselli P, Boumis E, Notari S, Nicastri E, Agrati C, Ippolito G, Gagliardi MC, Capobianchi MR and Ortona E (2021) Synergy Between Vitamin $D$ and Sex Hormones in Respiratory Functionality of Patients Affected by COVID-19.

Front. Pharmacol. 12:683529. doi: 10.3389/fphar.2021.683529
The outcome of COVID-19 appears to be influenced by vitamin D status of population. Although epidemiological data indicate that COVID-19 produces more severe symptoms and higher mortality in elderly in comparison to young patients and in men in comparison to women to date sex and age differences in vitamin D status in infected patients have not been evaluated yet. In this study we evaluated the levels of circulating 25(OH)D in patients hospitalized for COVID-19 divided accordingly to their sex and age. We also correlated $25(\mathrm{OH}) \mathrm{D}$ levels with patient's respiratory status (i.e., $\mathrm{PaO} 2 / \mathrm{FiO} 2$ ratio) and with sex hormones plasma levels to analyze the potential relationship of these parameters. We found no significant differences in plasma levels of $25(\mathrm{OH}) \mathrm{D}$ between pre- and postmenopausal female patients and age matched male patients. Interestingly, the $25(\mathrm{OH}) \mathrm{D}$ plasma levels positively correlated to $\mathrm{PaO} 2 / \mathrm{FiO} 2$ ratio only in young patients, regardless of their sex. We also found a significantly positive correlation between $17 \beta$-estradiol and $25(\mathrm{OH}) \mathrm{D}$ in elderly women and between testosterone and $25(\mathrm{OH}) \mathrm{D}$ in elderly men, supporting the role of sex hormones in maintaining $25(\mathrm{OH}) \mathrm{D}$ levels. In conclusion, we suggest that a synergy between vitamin $\mathrm{D}$ and sex hormones could contribute to the agerelated outcome of COVID-19.

Keywords: SARS-CoV-2, vitamin D, sex hormones, gender, sex differences

\section{INTRODUCTION}

The outcome of coronavirus disease 2019 (COVID-19) appears to be influenced by the interaction among genetic, hormonal and environmental factors. In this context, low levels of circulating 25hydroxyvitamin $\mathrm{D}[25(\mathrm{OH}) \mathrm{D}]$, the biomarker of vitamin $\mathrm{D}$ status, represent a risk factor for COVID-19 and 1,25(OH)2 vitamin $\mathrm{D}(3)$ (the active metabolite of vitamin $\mathrm{D}$ ) seems to play a protective role in this disease by controlling the cytokine storm, enhancing the production of antimicrobial peptides and maintaining the integrity of the epithelium (Pagano et al., 2020; Hutchings et al., 2021). Moreover, 1,25(OH)2 vitamin D(3), by increasing the expression of angiotensin-converting enzyme (ACE)2, the functional receptor for SARS-CoV-2, induces ACE2/Ang-(1-7)/MasR axis activity and inhibits renin and the ACE/Ang II/AT1R axis. This process leads to the protection against acute lung injury/acute respiratory distress syndrome (Xu et al., 2017; Gagliardi et al., 2020; Kumar et al., 2020; Malek Mahdavi, 2020). 
In the same vein, $17 \beta$-estradiol increases the expression of ACE2 also playing a protective role in COVID-19 (Seeland et al., 2020). Although epidemiological data indicate that COVID-19 produces more severe symptoms and higher mortality in elderly in comparison to young patients and in men in comparison to women (Pagano et al., 2020; Chen et al., 2021), to date, sex, and age differences in vitamin $\mathrm{D}$ status in infected patients have not been evaluated yet. Hence aim of this study was to analyze the levels of circulating $25(\mathrm{OH}) \mathrm{D}$ in patients hospitalized for COVID-19 divided accordingly to their sex and age. We also correlated $25(\mathrm{OH}) \mathrm{D}$ levels with patient's respiratory status and with sex hormones plasma levels to analyze the potential relationship of these parameters.

\section{METHODS}

To address this issue, we measured plasma levels of 25(OH)D, testosterone and $17 \beta$-estradiol from 160 adult patients (80 females and 80 males divided in four subgroups: A, 40 premenopausal females under 45 years; B, 40 males under 45 years; C, 40 post-menopausal females over 55 years; D, 40 males over 55 years) admitted to Lazzaro Spallanzani Hospital, Rome, Italy between March and September 2020, positive for SARS-CoV-2 by RT-PCR from nasopharyngeal swabs, and able to provide informed consent. Plasma samples were collected at clinical admission. Partial pressure of oxygen/inspired oxygen concentration ratio $(\mathrm{PaO} 2 / \mathrm{FiO} 2$ ratio), representing a valuable clinical measure of the patient's respiratory status, were recorded during clinical admission. ELISA kits for 25(OH)D (MyBioSource, San Diego, CA, United States) testosterone (R\&D Systems, Minneapolis, MN, United States) and 17 $\beta$-estradiol (Abcam, Cambridge, United Kingdom) were used according to manufactures' instructions. Statistical analysis was performed by the Mann-Whitney $U$ test and Spearman's rank correlation using GraphPad Prism (GraphPad Software, San Diego, CA, United States). A $p$ value $<0.05$ was considered statistically significant.

\section{RESULTS}

No significant differences in plasma levels of $25(\mathrm{OH}) \mathrm{D}$ were detected between female and male patients and among the four subgroups of patients divided according to sex and age (Figure 1A). Interestingly, the $25(\mathrm{OH}) \mathrm{D}$ plasma levels positively correlated to $\mathrm{PaO} 2 / \mathrm{FiO} 2$ ratio only in young patients (subgroups $A$ and $B, p=0,03$ and $p=0,01$ respectively, Figure 1B), regardless of the sex of patients. The here observed age-dependent vitamin $\mathrm{D}$ association with respiratory functionality in COVID-19 patients suggested the involvement of sex hormones in vitamin D effects. Hence, we correlated $25(\mathrm{OH}) \mathrm{D}$ levels with sex hormones plasma levels and we observed a significantly positive correlation between $17 \beta$-estradiol and $25(\mathrm{OH}) \mathrm{D}$ in elderly women (subgroup C, $p=0.01$, Figure 2A) and between testosterone and $25(\mathrm{OH}) \mathrm{D}$ in elderly men (subgroup $\mathrm{D}, p=$ 0.04, Figure 2B), supporting the role of sex hormones in maintaining $25(\mathrm{OH}) \mathrm{D}$ levels.

\section{DISCUSSION}

In this study we analyzed the $25(\mathrm{OH}) \mathrm{D}$ plasma levels in patients with COVID-19 divided accordingly to their sex and age and we found a positive correlation between vitamin $\mathrm{D}$ status and respiratory functionality only in young patients, regardless of their sex. This result was consistent to previous studies on the association of serum $25(\mathrm{OH}) \mathrm{D}$ concentration with the improved lung function, in both females and males (Ganji et al., 2020). We asked whether in young patients, sex hormones could impact vitamin $\mathrm{D}$ status and effects. Actually, estrogen has been suggested to enhance vitamin D actions, by increasing the expression of the nuclear vitamin $\mathrm{D}$ receptor gene (Cheema et al., 1989) and by decreasing the expression of CYP24A1, the cytochrome P450 component of the 25-hydroxyvitamin $\mathrm{D}(3)$-24-hydroxylase enzyme which catabolizes the active form of vitamin $\mathrm{D}$. In turn, vitamin $\mathrm{D}$ influences peripheral estrogen metabolism modulating in a tissue-specific way the function of the cytochrome P450 19 aromatase (CYP19), the enzyme that produces $17 \beta$-estradiol from testosterone (Lundqvist et al., 2011). Moreover, low levels of vitamin $\mathrm{D}$ have been also independently associated with low levels of testosterone in healthy middle-aged men (Giagulli et al., 2021; Papadopoulos et al., 2021). Accordingly, we found a significantly positive correlation between $17 \beta$ estradiol and $25(\mathrm{OH}) \mathrm{D}$ in elderly women and between testosterone and $25(\mathrm{OH}) \mathrm{D}$ in elderly men supporting the role of sex hormones in preserving $25(\mathrm{OH}) \mathrm{D}$ levels. A relationship between hormones of the hypothalamic-pituitary-testicular (HPT) axis and vitamin D status has been established (Lee et al., 2012). In this context, further studies are needed to evaluate gonadotropin levels in male patients in order to clarify the role of vitamin D/HPT axis in COVID-19.

In conclusion, it is tempting to hypothesize that the synergy between vitamin $\mathrm{D}$ and sex hormones could contribute to the age-related outcome of COVID-19. Controlled studies are needed to determine the role of vitamin $\mathrm{D}$ supplementation in combination with estrogens or androgens in improving respiratory function of female and male patients, respectively.

All in all, the collection, analysis and report of data on COVID-19 disaggregated by sex and age seem to be a duty to achieve the appropriateness of the prevention, treatment and control of the disease.

\section{INMI-ISS COVID-19 TEAM}

Simona Anticoli, Maria Bellenghi, Veronica Bordoni, Marta Camici1, Rita Casetti, Carlotta Cerva, Pierangelo Chinello, Eleonora Cimini, Davide Roberto Donno, Maria Luisa Dupuis, Francesca Faraglia, Katia Fecchi, Roberta Gagliardini, Germana 
A

$\square$ Females

Males
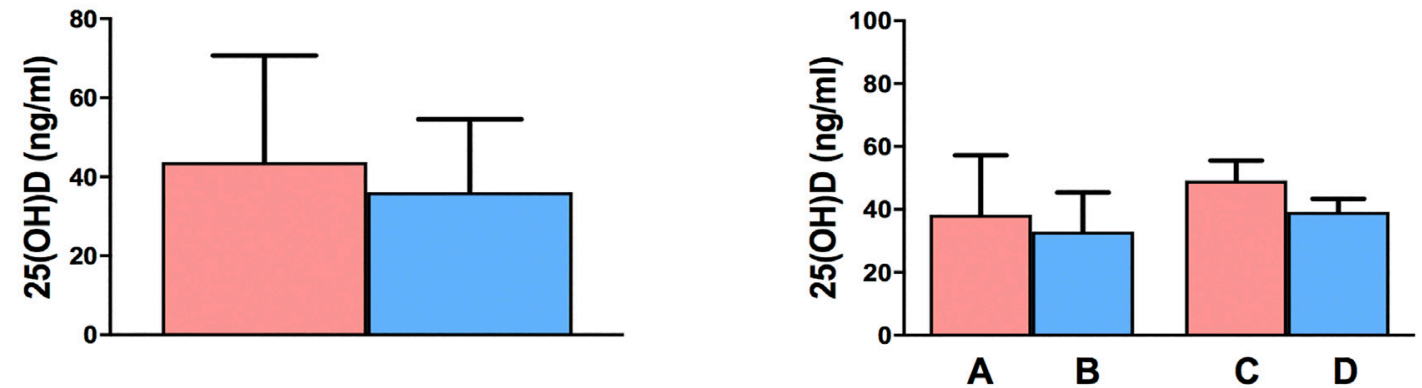

B

Females

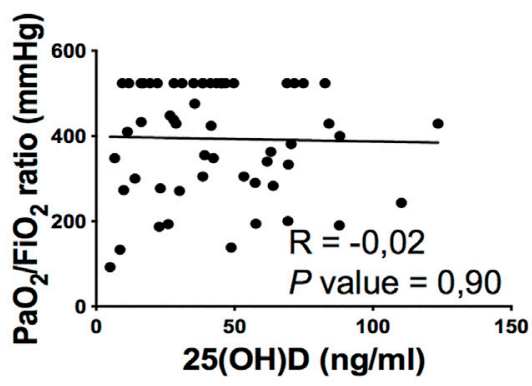

Males

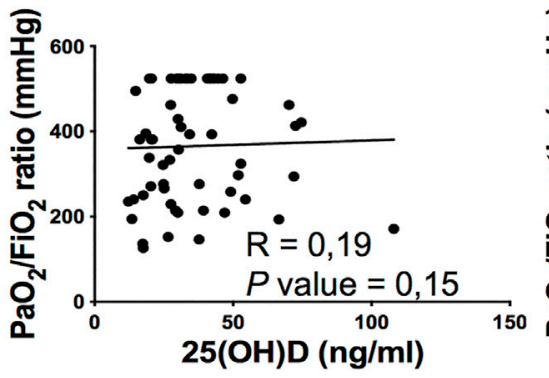

A: $<45$ yrs

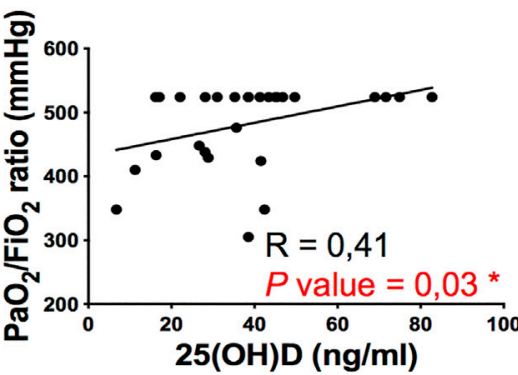

B: $<45$ yrs

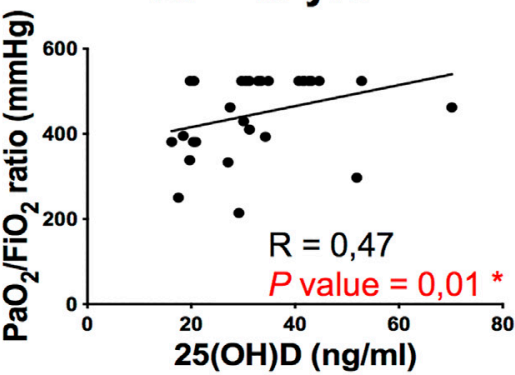

C: $>55$ yrs

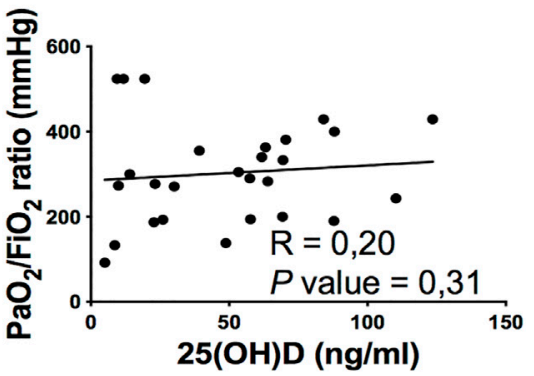

D: > 55 yrs

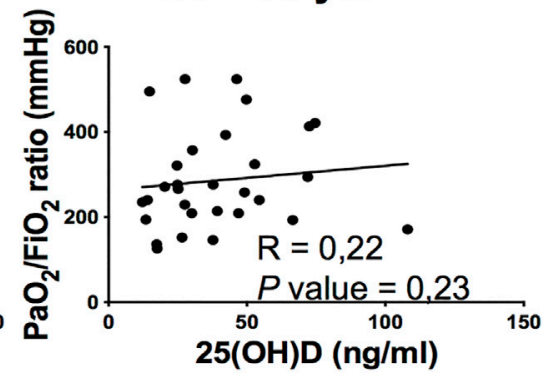

FIGURE 1 | Detection of plasma levels of 25(OH)D and its correlation with PaO2/FiO2 ratio in COVID-19 patients. (A) Analysis of plasma levels of 25(OH)D detected into female and male patients (left panel) and among the 4 subgroups of patients: A, 40 pre-menopausal females under 45 years; B, 40 males under 45 years; C, 40 postmenopausal females over 55 years; D, 40 males over 55 years. Data referred to plasma levels of $25(\mathrm{OH}) \mathrm{D}$ are reported as mean \pm SD. (B) Correlation and linear regression analysis of plasma levels of 25(OH)D and $\mathrm{PaO} 2 / \mathrm{FiO} 2$ ratio in female and male patients categorized into four groups: $\mathrm{A}, 40$ pre-menopausal females under 45 years (A: < $45 \mathrm{yrs}$ ); B, 40 males under 45 years (B: < $45 \mathrm{yrs}$ ); C, 40 post-menopausal females over 55 years (C: > $55 \mathrm{yrs}$ ); D, 40 males over 55 years (D: > 55 yrs). A significantly positive correlation between plasma levels of $25(\mathrm{OH}) \mathrm{D}$ and $\mathrm{PaO} 2 / \mathrm{FiO} 2$ ratio is observed in subgroups $\mathrm{A}$ and $\mathrm{B}$. The Spearman's rho (R) and $P$ values were determined using the Spearman's rank correlation analysis. Solid lines represent best fits as estimated by linear regression analysis. ${ }^{*}, P<0.05$ was considered statistically significant.

Grassi, Rachele Di Lorenzo, Manuela Macchione, Gaetano Maffongelli, Gianfranco Mattia, Eugenia Milozzi, Silvia Mosti, Giada Pontecorvi, Rossella Puglisi, Alessandra Sacchi, Eleonora Tartaglia, Serena Vita.

\section{DATA AVAILABILITY STATEMENT}

The data that support the findings of this study are available from the corresponding author. 


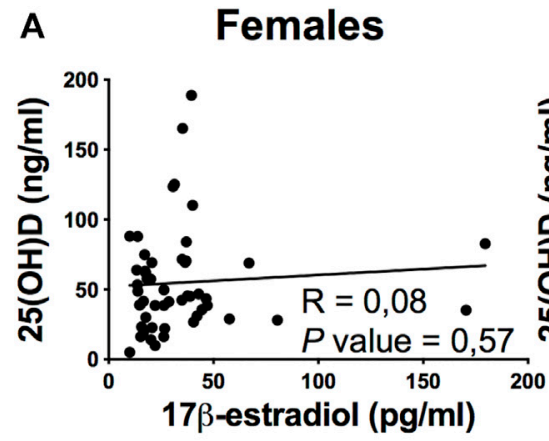

Males

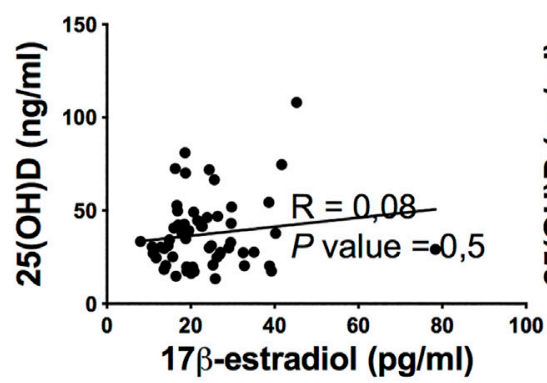

B

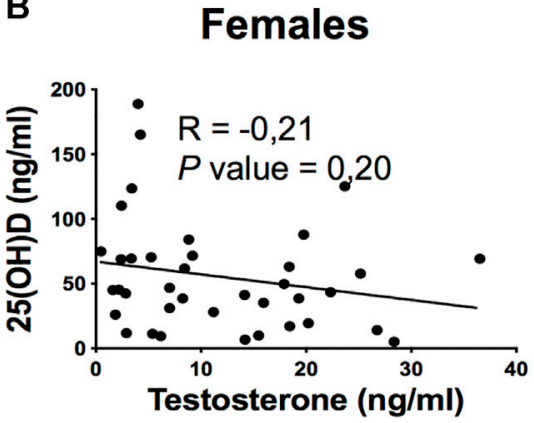

Males

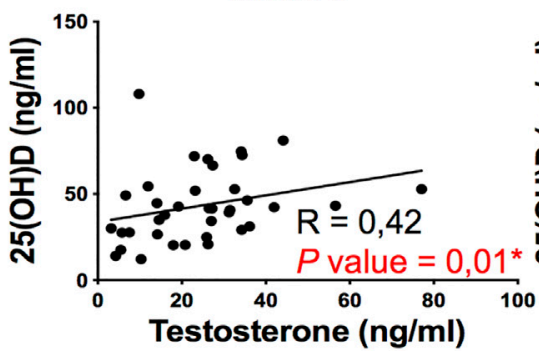

$A:<45$ yrs

C: $>55$ yrs

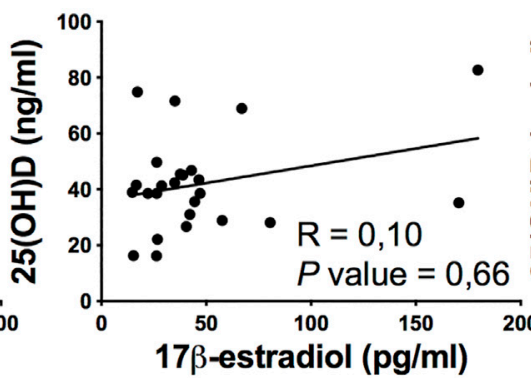

B: $<45$ yrs

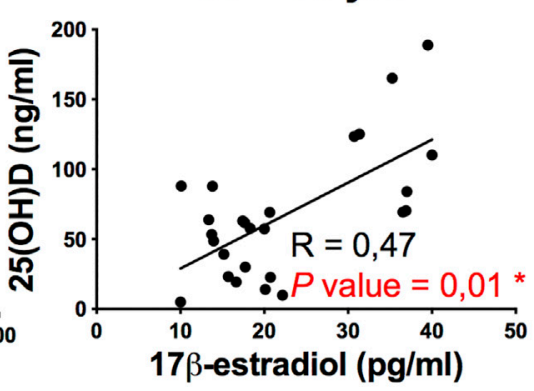

D: > 55 yrs
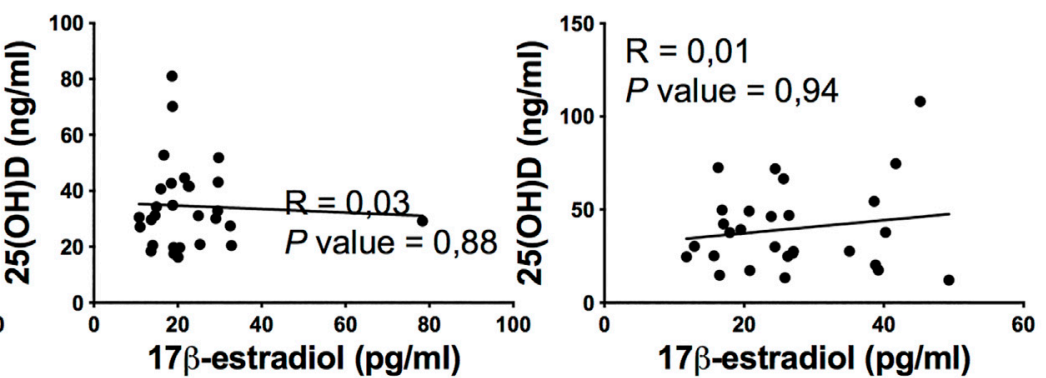

$A:<45$ yrs

C: $>55$ yrs
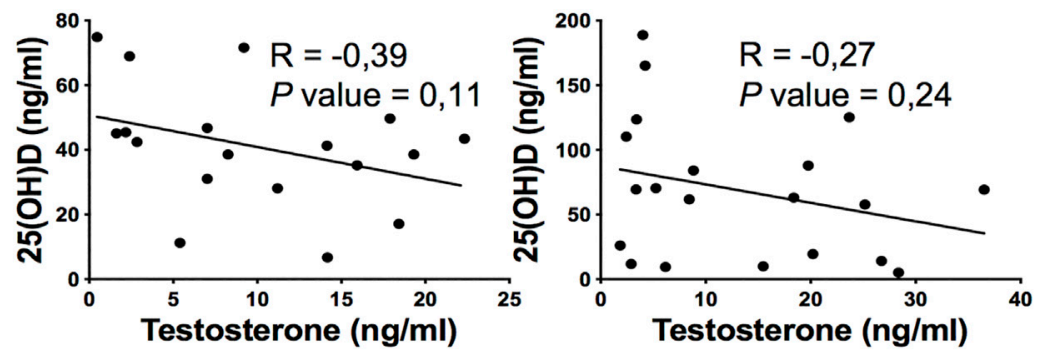

$B:<45$ yrs

D: > 55 yrs
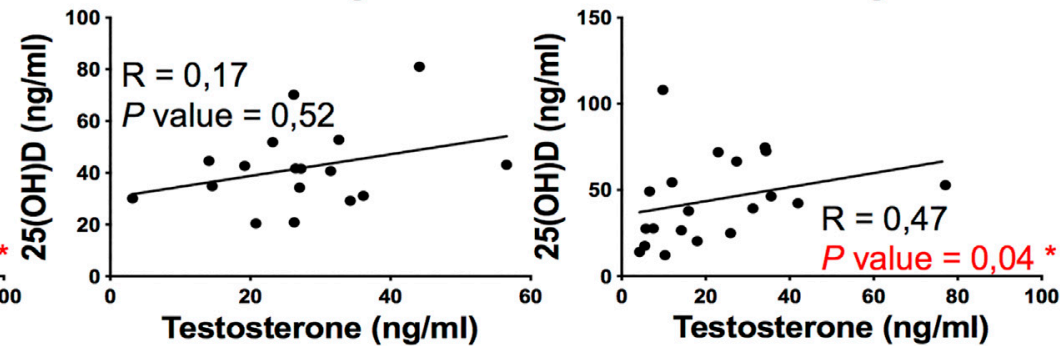

FIGURE 2 | Correlation of plasma 25(OH) vitamin D levels with 17ß-estradiol and Testosterone in COVID-19 patients. (A) Correlation and linear regression analysis of plasma levels of 25(OH)D and 17 $\beta$-estradiol in female and male patients categorized into four groups: A, 40 pre-menopausal females under 45 years (A: $<45$ yrs); B, 40 males under 45 years (B: < $45 \mathrm{yrs}$ ); C, 40 post-menopausal females over 55 years (C: > $55 \mathrm{yrs}$ ); D, 40 males over 55 years (D: > 55 yrs). A significantly positive correlation between plasma levels of 25(OH)D and 173 -estradiol is observed in subgroup C. (B) Correlation and linear regression analysis of plasma levels of 25(OH)D and testosterone into four groups. A significantly positive correlation between plasma levels of 25(OH)D and testosterone levels is observed in males and in subgroup $\mathrm{D}$. The Spearman's tho (R) and $P$ values were determined using the Spearman's rank correlation analysis. Solid lines represent best fits as estimated by linear by linear regression analysis. ${ }^{*}, P<0.05$ was considered statistically significant. 


\section{ETHICS STATEMENT}

The studies involving human participants were reviewed and approved by National Institute for Infectious Diseases, Lazzaro Spallanzani, IRCCS, Rome, Italy. The patients/participants provided their written informed consent to participate in this study.

\section{AUTHOR CONTRIBUTIONS}

DP and MTP performed experiments and analyzed data with equal contribution, $\mathrm{MP}$ and $\mathrm{AR}$ revised the manuscript, AA, GD, $\mathrm{NP}, \mathrm{FP}, \mathrm{PP}, \mathrm{EB}, \mathrm{SN}, \mathrm{EN}, \mathrm{CA}, \mathrm{GI}$, and MRC have participated in the research and in the acquisition of data, EO and MCG designed

\section{REFERENCES}

Cheema, C., Grant, B. F., and Marcus, R. (1989). Effects of Estrogen on Circulating "free" and Total 1,25-dihydroxyvitamin D and on the Parathyroid-Vitamin D axis in Postmenopausal Women. J. Clin. Invest. 83, 537-542. doi:10.1172/ JCI113915

Chen, Y., Klein, S. L., Garibaldi, B. T., Li, H., Wu, C., Osevala, N. M., et al. (2021). Aging in COVID-19: Vulnerability, Immunity and Intervention. Ageing Res. Rev. 65, 101205. doi:10.1016/j.arr.2020.101205

Gagliardi, M. C., Tieri, P., Ortona, E., and Ruggieri, A. (2020). ACE2 Expression and Sex Disparity in COVID-19. Cell Death Discov. 6, 37. doi:10.1038/s41420020-0276-1

Ganji, V., Al-Obahi, A., Yusuf, S., Dookhy, Z., and Shi, Z. (2020). Serum Vitamin D Is Associated with Improved Lung Function Markers but Not with Prevalence of Asthma, Emphysema, and Chronic Bronchitis. Sci. Rep. 10, 14118. doi:10. 1038/s41598-020-67967-7

Giagulli, V. A., Guastamacchia, E., Magrone, T., Jirillo, E., Lisco, G., De Pergola, G., et al. (2021). Worse Progression of COVID-19 in Men: Is Testosterone a Key Factor? Andrology 9, 53-64. doi:10.1111/andr.12836

Hutchings, N., Babalyan, V., Baghdasaryan, S., Qefoyan, M., Sargsyants, N., Aghajanova, E., et al. (2021). Patients Hospitalized with COVID-19 Have Low Levels of 25-hydroxyvitamin D. Endocrine 71, 267-269. doi:10.1007/ s12020-020-02597-7

Kumar, D., Gupta, P., and Banerjee, D. (2020). Letter: Does Vitamin D Have a Potential Role against COVID-19? Aliment. Pharmacol. Ther. 52, 409-411. doi:10.1111/apt.15801

Lee, D. M., Tajar, A., Pye, S. R., Boonen, S., Vanderschueren, D., Bouillon, R., et al. (2012). Association of Hypogonadism with Vitamin D Status: the European Male Ageing Study. Eur. J. Endocrinol. 166 (1), 77-85. doi:10.1530/EJE-11-0743

Lundqvist, J., Norlin, M., and Wikvall, K. (2011). 1a,25-Dihydroxyvitamin D3 Exerts Tissue-specific Effects on Estrogen and Androgen Metabolism. Biochim. the study and wrote the manuscript. All authors approved the submitted version.

\section{FUNDING}

This work was funded by the Italian Ministry of Health (COVID2020-12371817 and Ricerca Corrente, Linea 1).

\section{ACKNOWLEDGMENTS}

We acknowledge the National Institute for Infectious Diseases staff for their assistance in collecting the data.

Biophys. Acta (Bba) - Mol. Cel Biol. Lipids 1811, 263-270. doi:10.1016/j.bbalip. 2011.01.004

Malek Mahdavi, A. (2020). A Brief Review of Interplay between Vitamin D and Angiotensin-converting Enzyme 2: Implications for a Potential Treatment for COVID -19. Rev. Med. Virol. 30, e2119. doi:10.1002/ rmv.2119

Pagano, M. T., Peruzzu, D., Ruggieri, A., Ortona, E., and Gagliardi, M. C. (2020). Vitamin D and Sex Differences in COVID-19. Front. Endocrinol. 11, 567824 doi: $10.3389 /$ fendo. 2020.567824

Papadopoulos, V., Li, L., and Samplaski, M. (2021). Why Does COVID-19 Kill More Elderly Men Than Women? Is There a Role for Testosterone? Andrology 9, 65-72. doi:10.1111/andr.12868

Seeland, U., Coluzzi, F., Simmaco, M., Mura, C., Bourne, P. E., Heiland, M., et al. (2020). Evidence for Treatment with Estradiol for Women with SARS-CoV-2 Infection. BMC Med. 18, 369. doi:10.1186/s12916-020-01851-z

Xu, J., Yang, J., Chen, J., Luo, Q., Zhang, Q., and Zhang, H. (2017). Vitamin D Alleviates Lipopolysaccharide-Induced Acute Lung Injury via Regulation of the Renin-Angiotensin System. Mol. Med. Rep. 16, 7432-7438. doi:10.3892/mmr. 2017.7546

Conflict of Interest: The authors declare that the research was conducted in the absence of any commercial or financial relationships that could be construed as a potential conflict of interest.

Copyright (C) 2021 Peruzzu, Pagano, Pierdominici, Ruggieri, Antinori, D’Offizi, Petrosillo, Palmieri, Piselli, Boumis, Notari, Nicastri, Agrati, Ippolito, Gagliardi, Capobianchi and Ortona. This is an open-access article distributed under the terms of the Creative Commons Attribution License (CC BY). The use, distribution or reproduction in other forums is permitted, provided the original author(s) and the copyright owner(s) are credited and that the original publication in this journal is cited, in accordance with accepted academic practice. No use, distribution or reproduction is permitted which does not comply with these terms. 